\title{
Seroprevalence of Peste Des Petits Ruminants in Selected Districts of Siltie and Gurage Zones, South Region, Ethiopia
}

\section{Gizachew Hailegebreal}

Worabe Agricultural Research Center, South Agricultural Research Institute, PO Box 21, Worabe, Ethiopia

"Corresponding author: Gizachew Hailegebreal, Worabe Agricultural Research Center, South Agricultural Research Institute, PO Box 21, Worabe, Ethiopia, Tel: +53658462969; E-mail: gizachew05@gmail.com

Rec date: February 23, 2018; Acc date: March 23, 2018; Pub date: March 24, 2018

Copyright: $\odot 2018$ Hailegebreal G. This is an open-access article distributed under the terms of the Creative Commons Attribution License, which permits unrestricted use, distribution, and reproduction in any medium, provided the original author and source are credited.

\begin{abstract}
A cross-sectional study to investigate Peste des Petits Ruminants (PPR) seroprevalence was conducted between November 2014 and May 2015 in selected districts of Siltie and Gurage zones, south region, Ethiopia. A total of 390 serum samples were collected from sheep and goats. Competitive Enzyme Linked Immunosorbent Assay (c-ELISA) was used to detect the presence of antibodies in the sera of animals as indicator of exposure to the PPR virus. The total apparent prevalence was found to be $29.2 \%$ (114/390), indicating the spread of PPR virus throughout the study areas with silti and meskan districts experiencing the prevalence of $24.2 \%$ and $33 \%$, respectively. Study animals were categorized into two age groups as young and adult, with prevalence of $25.9 \%$ and $31.8 \%$, respectively. Out of total 390 samples, 240 serum samples were from male and 150 serum samples from female with prevalence of $29.6 \%(71 / 240)$ and $28.66 \%(43 / 150)$, respectively. In the two animal species the distribution of PPR virus was observed with the prevalence of $24.2 \%(46 / 190)$ in sheep and $34 \%(68 / 200)$ in goats. Statistically significant difference $(p<0.05)$ was observed between the two study areas and species whereas, the seroprevalence of PPR was statistically insignificant $(p>0.05)$ in other hypothesized risk factors. This study revealed circulation and subsequent endemic establishment of PPR in sheep and goats in the selected study areas. This disease is detrimental to small ruminant welfare and causes substantial economic losses, thereby affecting the livelihood of poor farmers and pastoralists. The need for implementing feasible control measures is, therefore, eminent to minimize the losses associated with the disease.
\end{abstract}

Keywords: Competitive; c-ELISA; Sheep; Goats; PPR; Seroprevalence

\section{Introduction}

The small ruminant population of Ethiopia is about 30.70 million sheep and 30.20 million Goats [1]. Owing to their high fertility, short generation interval and adaptation even in harsh environments, sheep and goats are considered as an important asset of poor framers. Small ruminants are exploited in the country for diverse purposes [2]. However, small ruminant production and productivity and producers' benefits are far below expectations due to different diseases and other factors. Peste des Petits Ruminants (PPR) is one of the important diseases affecting the productivity of small ruminant [3]. The disease is first described by Gargadennec and Lalanne from Ivory Coast in West Africa [4].

Peste des petits ruminants (PPR) is an acute, highly contagious, notifiable and economically important transboundary viral disease of goats and sheep, which is listed by the World Organization for Animal Health (OIE). The disease is characterized by high fever, ocular and nasal discharge, pneumonia, necrosis and ulceration of the mucous membrane and inflammation of gastro-intestinal tract leading to severe diarrhea [5]. Morbidity and mortality rates can be as high as 100 and 90 percent, respectively. The causative agent of this economically important disease of small ruminants is a Morbillivirus, the Peste des Petits Ruminants Virus (PPRV), under the family Paramyxoviridae of order Mononegavirales [6]. The virus is closely related to Rinderpest virus (RPV), another member of Morbillivirus genus, which causes similar disease in large ruminants [7].
Nowadays the disease is recognized as responsible for mortality and morbidity of sheep and goats across many countries of the world. Middle East and Arabian Peninsula; Iraq, Saudi Arabia, United Arab Emirates, Kuwait, Israel, Yemen and Oman are known to have the disease [8]. In Africa, PPR has been reported from different countries [9]. Prevalence of $57.6 \%$ has been reported in Uganda [10]. Similarly, in Tanzania and Nigeria seroprevalence rate of $46 \%$ and $55 \%$ were reported respectively $[11,12]$.

In Ethiopia, Clinical PPR was suspected in 1977 in afar region, east of the country [13]. Clinical and serological evidence of its presence confirmed in 1991 in Addis Ababa [14]. Gelagay has reported that $14.6 \%$ of sheep sampled along 4 roads from Debre Berhan to Addis Ababa were seropositive for PPR [15]. Waret-Szkuta et al. has also reported an overall seroprevalence of $15.3 \%$ in Afar, $4.6 \%$ in Amhara, $8.0 \%$ in Benishangul Gumuz, $1.7 \%$ in Oromia, $1.8 \%$ in SNNPR and $21.3 \%$ in Somalia regions of Ethiopia [16]. An overall seroprevalence record of $30.9 \%$ from sheep and goat in pastoral and agro-pastoral area of afar and Gambella region of Ethiopia has been reported [17]. Most recently, PPR prevalence of $47.5 \%$ and $48.43 \%$ has been reported from different parts of Tigray and Oromia regions of Ethiopia [18].

Despite production and disease challenges in Ethiopia; farmers prefer to rear sheep and goats including in the current study areas for their low cost of production, prolificacy, their adaptive capacity to environment through dynamic feeding behavior and fast reproduction cycle and growth rate. The degree to which sheep and goats survive to marketable age is one of the key indicators of the efficiency of their production. However, there is scarcity of information concerning the disease like PPR which is one of the major constraints in sheep and 
goat productivity, particularly in the present study areas. There is a need to assess the prevalence of the disease under village condition to recommend possible prevention and control strategies which enhance poverty alleviation program in the country. Therefore the present study was aimed to determine the seroprevalence and identify potential risk factors of Peste des petits ruminant's (PPR) in village sheep and goats.

\section{Materials and Methods}

\section{Study area}

The study was conducted in four Kebeles (the lowest administrative level in Ethiopia), distributed in two districts, silti district in Siltie administrative zone and Meskan district in Gurage zone of South regional state of Ethiopia. Silti district is located $150 \mathrm{~km}$ south of Addis Ababa, with Kibet being the main town. The district lies at the altitude ranges of 1650 up to 3100 masl and it has two agro-ecologies where $20.3 \%$ is highland (2300-3100 masl) and $70.70 \%$ mid altitude (1650-2300 masl). The district is dominantly Weyna Dega (mid altitude) in Agro-climatic condition. The annual average temperature of the area ranges from $12^{\circ} \mathrm{C}-25^{\circ} \mathrm{C}$. Meskan district is located $130 \mathrm{~km}$ south of Addis Ababa, with Butajira being the main town. It has varying climates zones from arid dry lowland areas around $1500 \mathrm{~m}$ altitude to cool mountainous areas above $2000 \mathrm{~m}$. The main wet season occurs between June and October while the remaining months are predominantly dry. All farmers included in the study use mixed croplivestock farming.

\section{Study design and sampling strategies}

A cross-sectional study was undertaken in Silti and Meskan districts of Siltie and Gurage zones, south regional state of Ethiopia from November 2014 to May 2015. A multi stage simple random sampling was utilized for selection of animals from individual households. First the two study districts were selected purposely based on their small ruminant population and importance. Then a list of kebeles within districts was obtained from the districts agricultural office and sampling kebeles were selected based on sheep and goat population, representation of the respective districts and accessibility. Villages within kebeles were selected by purposive sampling on the basis of prior information on the problem, farmers' cooperation, logistics, share of communal grazing land and accessibility. Finally, animals were examined to test the occurrence of the disease in the selected areas. Location, species, age and sex were concerned as hypothesized risk factors. In this study animals were categorized into two age groups. The first category was young between 6 months to 18 months and the second adult category was $>18$ months, all sheep and goats sampled belong to the local breed. All necessary epidemiological information was collected on individual animal bases using a structured questionnaire format.

\section{Sample size}

The sample size required for the present study was determined according to Thrusfield [19].

$\mathrm{n}=\mathrm{z}^{2} \times\left[\mathrm{P}_{\exp }\left(1-\mathrm{P}_{\exp }\right) / \mathrm{d}^{2}\right]$,

Where: $\mathrm{z}=1.96, \mathrm{P}_{\exp }=0.5$ (expected prevalence $50 \%$, since no previous study in the areas) and $\mathrm{d}=0.05$ (the desired level of precision or accuracy). The required sample size was accordingly calculated as $\mathrm{n}=384$, however, 390 sheep and goats were sampled for sero survey.

\section{Sample collection}

Blood samples $(4 \mathrm{ml})$ from the jugular vein of each animal were collected, using sterile needles and plain vacutainer tubes labelled with individual animal identification number. The blood samples were put at room temperature for about 24 hours in tilted position to obtain the serum. Sera were decanted into cryo-vials, identified and stored at $-20^{\circ} \mathrm{C}$ until screened for antibodies against natural PPR virus exposure using serological analysis.

\section{Laboratory examination}

Serum samples were analyzed by the National Veterinary Institute (NVI, Bishoftu, Ethiopia) using a competitive ELISA kit according to the instructions of the manufacturer (Institute for Animal Health, Pirbright Laboratory, UK). The ELISA micro-plates were read with an immunoskan reader (Flow laboratories, UK) with an inference filter of $492 \mathrm{~nm}$. The reader was connected to a computer loaded with ELISA Data Information (EDI) software (FAO/IAEA, Vienna, Austria), which was used to automate the reading and calculation of the competitive percentage values $(\mathrm{S} / \mathrm{N} \%)$. The samples result with competitive percentage $(\mathrm{S} / \mathrm{N} \%) \leq 50 \%$ were considered as positive.

\section{Data management and analysis}

Recorded data were entered into Excel for the analysis of different attributable factors. The descriptive statistics was employed to quantify the results of seroprevalence of PPR antibodies. The association of potential risk factors such as different location, species, sex and age were assessed using logistic regression employing windows Stata 13.

\section{Results}

A total of 390 serum samples were collected from two selected districts, Silti and Meskan. Out of which 29.2\% (114/390) were found to be seropositive for PPR antibody. In both districts, the distribution of PPR virus was observed with the prevalence ranging from $41 \%$ to $73 \%$ and significance difference was seen statistically $(\mathrm{p}<0.05)$. Out of total 390 samples, 240 serum samples were from male and 150 serum samples from female with prevalence of $29.6 \%$ (71/240) and $28.66 \%$ (43/150), respectively. The prevalence appeared between sex was not statistically significant ( $>0.05)$. In this study animals were categorized into two age groups. The first category was young between 6 months to 18 months and the second adult category was $>18$ months with their respective prevalence of $25.9 \%(44 / 170)$ and $31.8 \%$ (70/220). There was also no statistically significant difference between the two age groups ( $>0.05)$. In both species, 190 samples were from sheep and 200 samples from goats, prevalence of $24.2 \%(46 / 190)$ and $34 \%(68 / 200)$ was registered, respectively. The seroprevalence difference between the two species, goats having high prevalence was statistically significant $(\mathrm{p}<0.05)$ (Table 1).

\begin{tabular}{|l|l|l|l|l|l|}
\hline $\begin{array}{l}\text { Risk } \\
\text { factors }\end{array}$ & $\begin{array}{l}\text { Number } \\
\text { of } \\
\text { samples }\end{array}$ & $\begin{array}{l}\text { PPR } \\
\text { positive }\end{array}$ & $\begin{array}{l}\text { Prevalence } \\
\mathbf{( 9 5 \% ~ C l )}\end{array}$ & OR (95\% CI) & P-value \\
\hline Meskan & 221 & 73 & 33 & $\begin{array}{l}1.657 \\
(1.055-2.600)\end{array}$ & 0.028 \\
\hline Silti & 169 & 41 & 24.2 & & \\
\hline Female & 150 & 43 & 28.66 & $\begin{array}{l}1.04 \\
(0.665-1.626)\end{array}$ & 0.86 \\
\hline
\end{tabular}




\begin{tabular}{|l|l|l|l|l|l|}
\hline Male & 240 & 71 & 29.6 & & \\
\hline Young & 170 & 44 & 25.9 & $\begin{array}{l}0.771 \\
(0.495-1.202)\end{array}$ & 0.25 \\
\hline Adult & 220 & 70 & 31.8 & & \\
\hline Goats & 200 & 68 & 34 & $\begin{array}{l}1.67 \\
(1.07-2.60)\end{array}$ & 0.022 \\
\hline Sheep & 190 & 46 & 24.2 & & \\
\hline
\end{tabular}

sheep and goats as means of income generating and the vaccination coverage of the region is very minimal which might be the reason for contributing the high prevalence of the disease. Therefore, awareness should be created to farmers in small ruminant rearing practices and control measures should be put in place to minimize the loss associated with the disease.

\section{Acknowledgements}

This project was funded by South Agricultural Research Institute (SARI), South Regional Government of Ethiopia.

Table 1: Seroprevalence of PPR in relation to risk factors (Study areas, sex, age and species).

\section{Discussion}

The cross sectional study conducted on sheep and goat population of the present study revealed an overall seroprevalence of $29.2 \%$ (114/390), indicating the spread of PPR virus throughout the study areas. This result indicated that the PPR virus is circulating in the study areas and needs particular attention since it is one of the most economically important disease affecting both production and productivity of small ruminant. The overall seroprevalence of $29.2 \%$ observed in the current study was lower than Waret-Szkuta and Afera and which have been reported $52.5 \%, 46.53 \%$ and $48.43 \%$ from Somalia, Tigray and Oromia regions of Ethiopia, respectively $[16,18]$. Moreover the result of the current study is also lower, compared to the findings of 55\% in Nigeria [12], 55.2\% in Uganda [10], 55.95\% in Saudi Arabia [20], 61.8\% in Sudan [21]. The seroprevalence reports of $46 \%$ in India and $45.8 \%$ in Tanzania were also higher than the current report $[11,22]$. On the other hand, the current finding is relatively higher compared to the report by Banik et al. [23] in Bangladesh with the prevalence of $25 \%$. The difference in Agro climatic conditions, management of animals, veterinary service, cultural and social practices could be a reason for the variation between the current report and the mentioned other reports.

In this study statistically significant variation was observed between the study districts. The high seroprevalence of 33\% and relatively lower 24.2\% was registered in Meskan and Silti districts respectively. This could possibly be explained as difference in geographical location, various forms of stress factors as predisposing factors, management and/or infectious factors and bordering of Meskan district with areas which have high movement of animals. The current finding also revealed approximately equal prevalence of $29.6 \%$ in male and $28.66 \%$ in female which may resulted from equal exposure of male and female because they are herded together and communal grazing. The high seroprevalence of $31.8 \%$ registered in adult animals than young ones in the present study is in agreement to a report by Gari. However, there was no statistically significant difference in prevalence as far as sex and age categories were concerned. This is in agreement with previous finding [18]. The seroprevalence of PPR between the two species showed high prevalence of $34 \%$ in goats and $24.2 \%$ in sheep which was statistically significant $(p<0.05)$. This is because goats are affected more severely to PPR virus exposure compared to sheep and they exhibit striking clinical sign while sheep undergo mild form of the disease [24].

In conclusion, the presence of PPR virus, such a devastating virus poses a serious hindrance to small ruminant productivity; since they are the means of subsistence for millions in the least privileged parts of the country. In addition, most of the farmers in the study sites rear

\section{References}

1. Central statistical Agency (CSA) (2016/17) Federal Democratic Republic of Ethiopia. Central statistical agency, Agricultural sample survey. Volume 2: Report on Livestock and Livestock characteristics.

2. Abebe R, Tatek M, Megersa B, Sheferaw D (2011) Prevalence of Small Ruminant Ectoparasites and Associated Risk Factors in Selected Districts of Tigray Region, Ethiopia. Global Veterinaria 7: 433-437.

3. Gopilo A (2005) Epidemiology of Peste des Petits Ruminants virus in Ethiopia and molecular studies on virulence. $\mathrm{PhD}$ Thesis, National Polytechnic Institute of Toulouse.

4. Gargadennec L, Lalanne A (1942) La peste des petits ruminants. Bull Serv Zoo AOF 5: 15-21.

5. Gibbs EPJ, Taylor WP, Lawman MPJ, Bryant J (1979) Classification of the pestedes petits-ruminants virus as the fourth member of the genus Morbillivirus. Intervirology 11: 268-274.

6. Murphy FA, Gibbs EPJ, Horzinek MC, Studdert MJ (1999) Classification and Nomenclature of Viruses. In: Veterinary Virology. 3rd edn. Academic Press, New York, p: 413.

7. Couacy-Hymann ER, Bidjeh F, Angba KA, Domenech J, Diallo A (1995) Protection of goats against rinderpest by vaccination with attenuated peste des petits ruminants virus. Res Vet Sci 59: 106-109.

8. Mehmood A, Ali Q, Gadahi JA, Malik SA, Shah SI (2009) Detection of Peste des Petits Ruminants (PPR) virus antibodies in sheep and goat populations of the North West Frontier Province (NWFP) of Pakistan by competitive ELISA (cELISA). Vet World 2: 333-336.

9. Dhar P, Sreenivasa BP, Barrett T, Singh RP, Bandyopadhyay SK (2002) Recent epidemiology of peste des petits ruminants virus (PPRV). Vet Microbiol 8: 153-159.

10. Mulindwa B, Ruhweza SP, Ayebazibwe C, Mwiine FN, Muhanguzi D, et al. (2011) Peste des Petits Ruminants serological survey in Karamoja sub region of Uganda by competitive ELISA. Vet World 4: 149-152.

11. Senyael SE, Kapaga A, Kivaria F, Tinuga D, Joshua G, et al. (2009) Prevalence and distribution of Peste des petitis Virus in various districts in Tanzania. Vet Res Commun 10: 927-936.

12. Abdul-Dahiru E, Baba SS, Ambali AG, Egwu GO (2013) Seroprevalence of peste des petits ruminants among domestic small and large ruminants in semi-arid region of north-eastern Nigeria. Vet World 6: 807-811.

13. Pegram RG, Tereke F (1981) Observation on the health of Afar livestock. Ethiopian Vet J 5: 11-14.

14. Abraham PL, Kenfe G, Barrett T (1994) PPR in Ethiopian goats. Trop Anim Health Prod 26: 69-73.

15. Gelagay A (1996) Epidemiological and serological investigation of multifactorial ovine respiratory disease and vaccine trial on the high land of North Shewa, Ethiopia. In: Doctor in Veterinary Medicine Thesis, Faculty of Veterinary Medicine, Debre Zeyit.

16. Waret-Szkuta A, Roger F, Chavernac D, Yigezu L, Libeau G, et al. (2008) Peste des Petits Ruminants (PPR) in Ethiopia: Analysis of a national serological survey. BMC Vet Res 4: 34 .

17. Megersa B, Biffa D, Belina T, Debela E, Regassa A, et al. (2011) Serological investigation of Peste des Petits Ruminants (PPR) in small ruminants managed under pastoral and agro-pastoral systems in Ethiopia. Small Rumin Res 97: 134-138. 
Citation: Hailegebreal G (2018) Seroprevalence of Peste Des Petits Ruminants in Selected Districts of Siltie and Gurage Zones, South Region, Ethiopia. J Vet Sci Technol 9: 529. doi:10.4172/2157-7579.1000529

Page 4 of 4

18. Afera B, Hussien D, Amsalu K (2014) Seroprevalence of Peste Des Petit Ruminants in Goats of Southern Parts of Tigray Region. Global Veterinaria 12: 512-516.

19. Thrusfield M (2005) Veterinary Epidemiology. 2nd edn. London, Black Well Science, p: 600.

20. Elshemey TM, Mahmoud MA (2011) Seroprevalence of antibodies against peste des petits ruminants (PPR) virus in sheep and goat in Kingdom Saudia Arabia. Alexandria J Vet Sci 32: 175-182.

21. Abdalla AS, Majok AA, El Malik KH, Ali AS (2012) Seroprevalence of peste des petits ruminant virus (PPRV) in small ruminants in Blue Nile, Gadaref and North Kordofan States of Sudan. Journal of Public Health and Epidemiology 4: 59-64.
22. Balamurugan V, Saravanan P, Sen A, Rajak KK, Bhanuprakash V, et al. (2011) Sero-epidemiological study of peste des petits ruminants in sheep and goats in India between 2003 and 2009. Rev Sci Tech Off Int Epiz 30: 889-896.

23. Banik SC, Podder SC, Samad MA, Islam MT (2008) Sero-surveillance and immunization in sheep and goats against peste des Petits ruminants in bangladesh. Bangl J Vet Med 6: 185-190.

24. Taylor WP (1984) The distribution and epidemiology of PPR virus. preventive veterinary medicine. Transboundary Anim Dis 4: 157-166. 